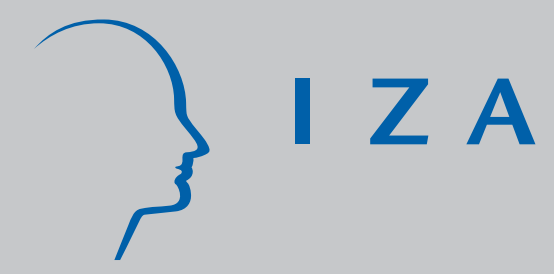

IZA DP No. 3389

Entrepreneurial Innovation and Sustained Long-Run Growth without Weak or Strong Scale Effects

Volker Grossmann

March 2008 


\title{
Entrepreneurial Innovation and Sustained Long-Run Growth without Weak or Strong Scale Effects
}

\author{
Volker Grossmann \\ University of Fribourg, CESifo \\ and IZA
}

Discussion Paper No. 3389

March 2008

\author{
IZA \\ P.O. Box 7240 \\ 53072 Bonn \\ Germany \\ Phone: +49-228-3894-0 \\ Fax: +49-228-3894-180 \\ E-mail: iza@iza.org
}

\begin{abstract}
Any opinions expressed here are those of the author(s) and not those of IZA. Research published in this series may include views on policy, but the institute itself takes no institutional policy positions.

The Institute for the Study of Labor (IZA) in Bonn is a local and virtual international research center and a place of communication between science, politics and business. IZA is an independent nonprofit organization supported by Deutsche Post World Net. The center is associated with the University of Bonn and offers a stimulating research environment through its international network, workshops and conferences, data service, project support, research visits and doctoral program. IZA engages in (i) original and internationally competitive research in all fields of labor economics, (ii) development of policy concepts, and (iii) dissemination of research results and concepts to the interested public.
\end{abstract}

IZA Discussion Papers often represent preliminary work and are circulated to encourage discussion. Citation of such a paper should account for its provisional character. A revised version may be available directly from the author. 
IZA Discussion Paper No. 3389

March 2008

\section{ABSTRACT \\ Entrepreneurial Innovation and Sustained Long-Run Growth without Weak or Strong Scale Effects ${ }^{*}$}

R\&D-based growth theory suggests that a larger population size raises either the long-run rate of economic growth ("strong scale effect") or the level of per capita income ("weak scale effect"), with far-reaching policy implications. However, for modern times there is little empirical support for strong scale effects and evidence in favor of weak scale effects is mixed, at best. This paper develops a simple overlapping-generations framework with endogenous occupational choice of heterogeneous agents and entrepreneurial innovations in which any form of scale effect is absent. A higher population growth rate has a negligible, possibly negative effect on the long-run growth rate of per capita income. Long-run growth is sustained also in absence of population growth and generally is policy-dependent.

JEL Classification: $\quad$ O10, O30, O40

Keywords: economic growth, endogenous technical change, entrepreneurial skills, population growth, scale effects

Corresponding author:

Volker Grossmann

Department of Economics

University of Fribourg

Bd. de Pérolles 90

$\mathrm{CH}-1700$ Fribourg

Switzerland

E-mail: volker.grossmann@unifr.ch

\footnotetext{
* I am grateful to David Stadelmann and Thomas Steger for valuable comments and suggestions. I also profited from illuminating discussions with Holger Strulik and seminar participants at the University of Hohenheim.
} 


\section{Introduction}

Endogenous growth theory captures that knowledge accumulates through the arrival of innovations which are an outcome of profit-oriented R\&D investments. Any set of instructions for a quality-improvement, process innovation or a new good can be applied without non-rivalry to the manufacturing process. It has been argued that, therefore, the size of population inevitably affects either the long-run growth rate of per capita income ("strong scale effect") or its long-run level ("weak scale effect"). Strong scale effects, featured by first-generation models of endogenous growth (Romer, 1990; Grossman and Helpman, 1991; Aghion and Howitt, 1992), are inconsistent with the fact that the number of researchers has substantially increased over time while productivity growth rates have remained relatively stable (see Jones 1995a,b). ${ }^{1}$ They were successfully removed in a series of papers (e.g. Jones, 1995a; Dinopoulos and Thompson, 1998; Peretto, 1998; Segerstrom, 1998; Young, 1998; Howitt, 1999). These contributions instead predict the weak form of scale effects (Jones, 1999). In fact, conventional wisdom holds that "the weak form of scale effects is so inextricably tied to idea-based growth that rejecting one is largely equivalent to rejecting the other" (Jones, 2005, p. 1089).

Dependency of long-run per capita income on population size has far-reaching policy implications. For instance, it suggests that goods market integration, by increasing the size of the economy, raises living standards. ${ }^{2}$ Moreover, it suggests that the demographic change which is projected for many developed countries will impede advancements of the world's technological frontier. So-called "semi-endogenous" growth models (e.g. Jones, 1995a, 2002, 2005) even suggest that economic growth is driven exclusively by population growth in the long-run, as an implication of weak scale effects. It may therefore be argued on basis of R\&D-based growth theory that governments should take action to raise fertility.

\footnotetext{
${ }^{1}$ However, support in favor of strong scale effects has been provided by Kremer (1993) for historical (pre-modern) times.

${ }^{2}$ From an empirical point of view, however, the link between trade liberalization and per capita income is subject to a lively debate which yet has not reached a consensus (see e.g. Rodrik, Subramanian and Trebbi, 2004, and the references therein).
} 
In view of international linkages and associated international technological spillovers it is beside the point to dismiss scale effects by arguing that small economies like Luxembourg, Switzerland or Hongkong are among the richest. Cross-country studies which examine the impact of larger population size on per capita income therefore account for international trade relations. They provide mixed evidence in support of weak scale effects. For instance, Hall and Jones (1999) regress per capita income on population size while controlling for instrumented "social infrastructure" - an index which includes a measure of trade openness. They find that population size enters insignificantly. Frankel and Romer (1999) show that when trade volumes are instrumented for by geographical variables "there is a positive [...] relation between country size and income per person", which however is "only marginally significant" (p. 387). Rodrik, Subramanian and Trebbi (2004) redo a similar analysis by using instruments for measures of institutional quality as well, in addition to instrumenting trade volumes. In contrast to Frankel and Romer (1999), they find insignificant and sometimes even negative effects of larger population size on per capita income. ${ }^{3}$ Also consistent with the absence of scale effects, another strand of literature suggests that the impact of an increase in the population growth rate on the growth rate of per capita income is either insignificant or negative (Brander and Dowrick, 1994; Ahituv, 2001; Kelley and Schmidt, 2005). ${ }^{4}$

This paper develops a simple vertical innovation model where a larger population size not only leaves the long-run growth rate unaffected but also the level of per capita income. As not only strong scale effects but also weak ones are absent, faster population growth may not be positively related to the long-run growth rate of per capita income. Long-run economic growth is sustained also if there is no population growth

\footnotetext{
${ }^{3}$ Similar evidence is provided by Bolaky and Freund (2006). See also Rose (2006), who employs a large panel data set to examine the effect of population size of a country on many economic and social indicators (including GDP per capita). He concludes that small and large countries are not systematically different.

${ }^{4}$ It has been argued that semi-endogenous growth theory may, nevertheless, not be inconsistent with the latter finding. If one allows for dilution effects of larger population size, higher population growth depresses the capital-labor ratio in the transition to a steady state, similar to neoclassical growth theory. According to this reasoning, we do not yet observe steady state dynamics and a positive relationship between population growth and income growth eventually may materialize (Jones, 2002, 2005).
} 
and generally is policy-dependent.

In the proposed model, heterogeneous individuals live in overlapping generations and decide whether or not to become entrepreneur. Entrepreneurial ability is complementary to the $\mathrm{R} \& \mathrm{D}$ process in determining the quality of final goods. The focus on entrepreneurial innovation is non-standard in the endogenous growth literature. ${ }^{5}$ This is surprising in view of a fast growing literature which has identified an important role of entrepreneurs for productivity growth. For instance, Baumol, Litan and Schramm (2007) argue that the driving force behind the advanced countries' IT revolution and the associated productivity growth surge in the last 15 years is due to the development and growth of innovative entrepreneurial companies, like Microsoft, Intel, eBay, Amazon, Google, or Federal Express. In another recent paper, van Praag and Versloot (2007) provide a meta-study of 57 recent high-quality studies on the contribution of entrepreneurs (young firms with less than 100 employees) for macroeconomic performance. They conclude that entrepreneurial firms "engender relatively much [...] productivity growth and produce and commercialize high quality innovations" (p. 1).

In contrast to the previous literature and reflecting the focus on entrepreneurial innovation of heterogeneous final good producers, the framework abstains from assuming that the aggregate production level is a function of some composite commodity index of imperfectly substitutable intermediate products (Dixit and Stiglitz, 1977; Ethier, 1982). The equilibrium number of firms is proportional to the size of the workforce in the long-run. Although the entry process is modelled differently, this feature is also contained in several vertical innovation models which remove strong scale effects (e.g. Peretto, 1998; Young, 1998) and is consistent with empirical evidence (Laincz and Peretto, 2006). In the proposed framework, it also removes weak scale effects.

Dalgaard and Kreiner (2001) as well as Strulik (2005, 2007) have shown that scaleinvariant endogenous growth is possible in infinite-horizon models with an ever increasing human capital level, like in Lucas (1988). For instance, in Dalgaard and Kreiner (2001), the aggregate human capital level is proportional to aggregate final output.

\footnotetext{
${ }^{5}$ For notable exceptions, see e.g. Clemens (2006) as well as García-Peñalosa and Wen (2008). They consider occupational choice in the context of entrepreneurial risk-taking.
} 
As a result, higher population growth exerts a congestion effect on human capital per worker. It has the same impact as an increase in the depreciation rate of the per capita level of human capital (Strulik, 2005, 2007). Consequently, long-run R\&D-based growth is not necessarily related to population growth in a positive way. The overlapping generations structure in this paper abstains from assuming infinite human capital accumulation. For simplicity, and to put the contrast to the previous literature in its sharpest relief, human capital is exogenous.

The paper is structured as follows. Section 2 highlights scale effect properties in the previous growth literature, by distinguishing between horizontal and vertical innovations. Section 3 develops and analyzes a vertical innovation model with endogenous entrepreneurship which removes scale effects. It contrasts the basic assumptions with those in the analysis of section 2 to clarify the sources of scale effects in the previous literature. The last section concludes.

\section{Scale Effects and Endogenous Growth}

This section briefly sketches the previous literature on endogenous growth by highlighting its scale effect properties.

Consider first a typical, linear homogenous production function of final output in endogenous growth theory, of the form

$$
Y_{t}=\left(X_{t}\right)^{\gamma}\left(L_{t}^{Y}\right)^{1-\gamma}, \text { with } X_{t}=\left(\int_{0}^{N_{t}}\left(A_{i t}\right)^{1-\gamma}\left(x_{i t}\right)^{\gamma} d i\right)^{1 / \gamma}
$$

$0<\gamma<1$, where $t$ is a time index, $L^{Y}$ is manufacturing labor, $X$ is the quantity of a composite good consisting of (a mass of) $N$ intermediate capital inputs, and $x_{i}$ and $A_{i}$ denote the quantity and the quality of intermediate good $i$, respectively. Intermediate goods are produced by monopolistically competitive firms, with one variety per firm. The labor force, $L$, is supplied inelastically to a perfect labor market. It grows at a constant rate, $g_{L} \geq 0$. 


\subsection{Horizontal Innovations}

In models of horizontal innovations (e.g. Romer, 1990; Jones, 1995a), R\&D investment is targeted to generate blueprints for new intermediate goods. That is, the number of intermediate products, $N_{t}$, is a measure of the economy's knowledge stock in $t$. As the focus is on horizontal innovations, quality indices of capital inputs are normalized to unity in this subsection, $A_{i t}=1$. In a symmetric steady state equilibrium we have $x_{i t}=\bar{x}_{t}$ and thus $Y_{t}=N_{t}\left(\bar{x}_{t}\right)^{\gamma}\left(L_{t}^{Y}\right)^{1-\gamma}$. Suppose that one unit of foregone consumption can be transformed into one unit of any intermediate good. That is, $K \equiv N \bar{x}$ is the total capital input. Consequently, output per worker is given by

$$
y_{t} \equiv \frac{Y_{t}}{L_{t}}=N_{t}\left(\tilde{k}_{t}\right)^{\gamma}\left(l_{t}^{Y}\right)^{1-\gamma}
$$

where $\tilde{k} \equiv K /(N L)$ is the knowledge-adjusted capital-labor ratio and $l^{Y} \equiv L^{Y} / L$ is the fraction of labor devoted to manufacturing. Time in continuous. When $L^{R}$ units of labor are allocated to R\&D, knowledge accumulates according to

$$
\dot{N}_{t}=\delta\left(N_{t}\right)^{\phi} L_{t}^{R}
$$

$\delta>0$, where Romer (1990) assumes $\phi=1$ and Jones (1995a) assumes $\phi<1$. $^{6}$ In both papers, there is a balanced growth equilibrium (BGE) in which the fraction of labor devoted to R\&D and manufacturing, $\lambda \equiv L^{R} / L$ and $l^{Y}=1-\lambda$, respectively, as well as the knowledge-adjusted capital-labor ratio, $\tilde{k}$, are constant over time and scaleinvariant. Hence, the long-run growth rate of per capita income equals the growth rate of the number of blueprints, $N$. Let $g_{z}$ denote the growth rate of a variable $z$ and $k=K / L$ the capital-labor ratio. We have $g_{y}=g_{N}=g_{k}=\delta N^{\phi-1} L^{R}$. If $\phi=1$, then $g_{y}=\delta \lambda L$, where $L^{R}=\lambda L$ has been used. Thus, in BGE (where $\lambda$ is constant over time) the per capita income growth rate is increasing in the size of the labor force, $L$ (strong scale effect). If $\phi<1$, by noting that $g_{N}=\delta N^{\phi-1} \lambda L$ is time-invariant in

\footnotetext{
${ }^{6}$ For the production function employed here, $Y_{t}=\left(L_{t}^{Y}\right)^{1-\gamma} \int_{0}^{N_{t}}\left(x_{i t}\right)^{\gamma} d i$, which is a simplified technology of Romer (1990), the case $\phi=1$ is analyzed comprehensively in a recent survey article (Grossmann and Steger, 2007). Jones (1995a) fully treats the case $\phi<1$ for this technology.
} 
a BGE, we obtain from differentiating with respect to time that $g_{N}=(1-\phi)^{-1} g_{L}$. Combining $g_{N}=(1-\phi)^{-1} g_{L}$ and $g_{N}=\delta N^{\phi-1} \lambda L$ implies $N=\left[(1-\phi) \delta \lambda L / g_{L}\right]^{\frac{1}{1-\phi}}$. Thus, $N$ is increasing in $L$. In view of (2) together with the properties that $\tilde{k}$ and $l^{Y}$ are time-invariant in the long-run, this shows that there are weak scale effects, if $\phi<1$. Moreover, the growth rate of per capita income, $g_{y}=(1-\phi)^{-1} g_{L}$, is proportional to the population growth rate and policy-independent ("semi-endogenous growth"). There is no exponential economic growth in the long run unless the population size grows: if $g_{L}=0$, then $g_{y}=0 .^{7}$

\section{$2.2 \quad$ Vertical Innovations}

Next consider vertical innovations in a simple discrete time framework under technology (1), i.e., quality improvements of intermediate goods. Higher quality of a good means that it has higher productivity in the final goods sector. Each period, firms may require a fixed labor input, $f \geq 0$ (e.g. administrative labor for market entry and maintenance of a firm). There is free entry of firms. The number of intermediate goods, $N$, is determined by the condition that net profits of firms are zero in equilibrium. $N$ is constant along a balanced growth path. Quality-improvements occur according to

$$
A_{i t}=\bar{A}_{t-1} h\left(l_{i t-1}^{R}\right)
$$

where $l_{i t-1}^{R}$ is R\&D labor input in firm $i$ and $\bar{A}_{t-1}$ is the average quality of goods in $t-1$. Access to last period's stock of knowledge reflects the standard "standing on shoulders" effect. $\bar{A}_{0}$ is given and positive. $h$ is an increasing and strictly concave function. (It also fulfills other standard conditions which ensure an interior solution for the R\&D investment decision.) Moreover, $h(0)=1$. That is, if a firm does not invest in $\mathrm{R} \& \mathrm{D}, A_{i t}=\bar{A}_{t-1}$.

One unit of foregone consumption can be transformed into one unit of capital input. Hence, the marginal production costs in $t$ are equal to the interest rate, $r_{t}$. With

\footnotetext{
${ }^{7}$ Groth, Koch and Steger (2008) show that the economy still may grow without bounds even if $g_{L}=0$; however, long run growth then is less than exponential.
} 
production function (1) and perfect competition in the final goods sector, the inverse demand function of the representative final goods producer for capital input $i$ is given by $p_{i}=\gamma\left(A_{i} L^{Y} / x_{i}\right)^{1-\gamma}$. Thus, an intermediate good monopolist $i$, by maximizing profits $\left(p_{i}-r\right) x_{i}$, chooses price $p_{i}=r / \gamma$ and thus output $x_{i}=\left(\gamma^{2} / r\right)^{\frac{1}{1-\gamma}} A_{i} L^{Y}$. The model is fully solved in Appendix A by assuming the standard intertemporal utility function $U=\sum_{t=0}^{\infty} L_{t} \rho^{t} \ln c_{t}, 0<\rho<1$, of an infinitely-living representative dynasty, where $c$ denotes per capita consumption. It is shown that there exists a symmetric BGE (i.e., $A_{i t}=\bar{A}_{t}$ for all $i$ ). Substituting the solution for $x_{i}$ into (1), we thus find that per capita income is given by

$$
y_{t}=\bar{A}_{t}\left(\frac{\gamma^{2}}{r_{t}}\right)^{\frac{\gamma}{1-\gamma}} n_{t} l_{t}^{Y} L_{t}
$$

where $n \equiv N / L$ (also recall $\left.l^{Y}=L^{Y} / L\right)$. Appendix A shows that in a BGE an increase in population size $(L)$ induces a proportional increase in the number of goods, $N$. In addition to $n=N / L$, also $l^{Y}$ and $r$ are independent of scale and time-invariant in BGE. This implies that R\&D employment per firm in BGE, $l^{R *}$, remains unaffected when population size changes. Thus, the growth rate of productivity measure $\bar{A}$ is independent of scale as well: according to $(4), g_{\bar{A}}=h\left(l^{R *}\right)-1$. This illustrates the basic idea of models without strong scale effects like Peretto (1998), Young (1998), Dinopoulos and Thompson (1998) and Howitt (1999). However, it follows from (5) that in BGE per capita income is proportional to population size $L$; thus, there are weak scale effects. Moreover, in BGE per capita income grows at rate $g_{y}=g_{\bar{A}}+g_{L} \cdot{ }^{8}$ Hence, unlike in semi-endogenous growth models, long-run economic growth is sustained even if there is no population growth $\left(g_{L}=0\right)$. One can also show that $g_{y}$ may be affected by economic policy. ${ }^{9}$

\footnotetext{
${ }^{8}$ To be precise, as time is assumed to be discrete, this is the approximate growth rate (use $g_{\bar{A}} g_{L} \approx$ $0)$.

${ }^{9}$ For instance, a subsidy to R\&D investment (financed by a lump-sum tax), raises the equilibrium R\&D input per firm, $l^{R *}$, and thus the rate of productivity growth, $g_{\bar{A}}=h\left(l^{R *}\right)-1$, if $f>0$ but not if $f=0$. See Grossmann (2008).
} 


\section{A Framework with Entrepreneurial Innovation}

Now consider the following overlapping generations, discrete time framework with an endogenous mass ("number") of heterogeneous entrepreneurs who can invest in R\&D. Both goods and factor markets are perfect.

\subsection{The Model}

Denote now by $N_{t}$ the number of entrepreneurs in $t$, where $N_{0}>0$ is given. They produce a homogenous consumption good, the "numeraire", according to

$$
q_{i t}=\left(A_{i t}\right)^{1-\alpha} x_{i t}^{\alpha},
$$

$0<\alpha<1$, where $q_{i}$ is final output of firm $i, x_{i}$ is its input of a homogenous producer good, and $A_{i}$ is a productivity index. ${ }^{10}$ Thus, the gross domestic product (GDP) of the economy is equal to the "sum" of the value of all entrepreneurs' final output levels:

$$
Y_{t}=\int_{0}^{N_{t}} q_{i t} d i .
$$

That is, unlike in standard endogenous growth models, which employ a technology similar to (1), aggregate output of final goods is not a function of a composite commodity index of imperfectly substitutable capital goods. It rather reflects the definition of GDP in national accounts. ${ }^{11}$

Entrepreneurs may differ in ability, $a_{i}$, which is positively associated with the productivity level of their firm, $A_{i}$, for given R\&D effort. In each generation, entrepreneurial ability is distributed according to a time-invariant and scale-invariant, cumulative distribution function, $\Phi(a)$. The associated density function has support $[0, \bar{a}], \bar{a}>0$.

\footnotetext{
${ }^{10}$ The assumption that the producer $\operatorname{good}(x)$ is the only rented factor in the final goods sector is made for simplicity. One could easily extend the technology to combine labor with the producer good, as long as there are decreasing private returns in the rented factors. Under the assumption of perfect competition, these imply positive profits of entrepreneurs (the residual claimants). Otherwise, individuals would not have an incentive to become entrepreneur.

${ }^{11}$ One may alternatively interpret the output of entrepreneurs as intermediate goods, which are perfectly substitutable for final goods production of a representative firm.
} 
Entrepreneurs may invest in $R \& D$ one period in advance of production. R\&D affects productivity, $A_{i}$, according to

$$
A_{i t}=\bar{A}_{t-1} h\left(\ell_{i t-1}^{R}\right)
$$

where $\ell_{i}^{R}=a_{i} l_{i}^{R}$ are efficiency units of R\&D labor when entrepreneur $i$ (with ability $a_{i}$ ) employs $l_{i}^{R} \mathrm{R} \& \mathrm{D}$ workers; average productivity, $\bar{A}_{t-1} \equiv\left(1 / N_{t-1}\right) \int_{0}^{N_{t-1}} A_{i t-1}$, measures the stock of knowledge in $t-1 . \bar{A}_{0}>0$ is given. Function $h$ is, again, increasing and strictly concave; it also fulfills $h(0)=1$ and standard boundary conditions. Opening up a new firm requires a fixed labor input, $f>0$. Fixed costs are necessary for the existence of equilibrium, as will become apparent.

Total output of the intermediate good is denoted by $X$. It is produced according to the constant-returns to scale technology

$$
X_{t}=\left(K_{t}\right)^{\beta}\left(\bar{A}_{t} L_{t}^{X}\right)^{1-\beta}
$$

$0<\beta<1$, where $K$ denotes capital input (in units of the final good) and $L^{X}$ is labor input in the producer good sector. Thus, an increase in the contemporaneous stock of knowledge, $\bar{A}$, is labor-saving in the intermediate good sector. This may capture, for instance, a cross-sectional knowledge spillover effect and is required for existence of a BGE. ${ }^{12}$ For simplicity, capital can freely be rented at an internationally given interest rate, $\bar{r}>0 .{ }^{13}$ In equilibrium, total output of the intermediate good is equal to its aggregate demand, $X=\int_{0}^{N} x_{i} d i$.

Individuals live two periods in overlapping generations, where $L_{t}$ is the size of the population born in period $t$. It grows according to $L_{t+1}=\left(1+g_{L}\right) L_{t}$, where $L_{0}>0$. In the first period of life, each individual inelastically supplies one unit of labor to the

\footnotetext{
${ }^{12}$ The proposed framework does not resolve the well-known problem that knife-edge conditions of some sort are required to obtain a BGE in models of endogenous technical change (Jones, 2005).

${ }^{13}$ Appendix $\mathrm{C}$ deals with the case of a closed economy, where the interest rate is endogenous. The main result, that larger population size has no effect on GDP per worker in a steady state equilibrium, remains unchanged. However, ensuring uniqueness of a BGE of the closed economy version of the model would require further assumptions and the analysis would be significantly less tractable, without delivering important additional insights.
} 
labor market and chooses savings for old age. Moreover, individuals decide whether or not to open a final good firm and, if they choose to do so, how much to invest in R\&D. In the second period, individuals compete in the final good sector if having become entrepreneur or else retire. Each member $i$ of generation $t-1$ maximizes the standard utility function

$$
u\left(c_{i t-1,1}, c_{i t, 2}\right)=\ln c_{i t-1,1}+\rho \ln c_{i t, 2},
$$

$0<\rho<1$, where $c_{i t-1,1}$ and $c_{i t, 2}$ denote the consumption level in the first and second period of life, respectively.

Finally, in order to examine whether and, if yes, how economic growth depends on public policy in the long-run, suppose the government may levy a R\&D subsidy, at rate $\tau \in[0,1)$. It is financed by a proportional value-added consumption tax with a time-invariant tax rate. It will be easy to see that, under the log-linear utility function (10), such a tax does not affect entry or R\&D investment decisions. ${ }^{14}$

\subsection{Equilibrium Analysis}

Let $p_{t}$ be the price of the intermediate good. As implied by (6), entrepreneur $i$ born in $t-1$ chooses intermediate input demand according to $p_{t}=\alpha\left(A_{i t} / x_{i t}\right)^{1-\alpha}=\alpha q_{i t} / x_{i t}$. Under perfect competition, price $p$ equals marginal production costs in the intermediate goods sector, denoted by c. Thus, $x_{i}=(\alpha / \mathfrak{c})^{\frac{1}{1-\alpha}} A_{i}$. Using $p x_{i}=\alpha q_{i}$, the cash-flow of entrepreneur $i, \pi_{i} \equiv q_{i}-p x_{i}$, is given by $\pi_{i}=(1-\alpha) q_{i}$, where $q_{i}=(\alpha / \mathfrak{c})^{\frac{\alpha}{1-\alpha}} A_{i}$. Using (8), we obtain

$$
\pi_{i t}=(1-\alpha)\left(\frac{\alpha}{\mathfrak{c}_{t}}\right)^{\frac{\alpha}{1-\alpha}} \bar{A}_{t-1} h\left(\ell_{i t-1}^{R}\right)
$$

for the cash-flow of entrepreneur $i$ in $t$.

Moreover, substitute $q_{i}=(\alpha / \mathfrak{c})^{\frac{\alpha}{1-\alpha}} A_{i}$ into (7) to find that final output per worker in $t, y_{t} \equiv Y_{t} / L_{t}$, is given by

$$
y_{t}=\bar{A}_{t}\left(\frac{\alpha}{\mathfrak{c}_{t}}\right)^{\frac{\alpha}{1-\alpha}} n_{t} .
$$

\footnotetext{
${ }^{14}$ Unlike in standard models, a lump-sum tax (typically assumed to finance R\&D subsidies) would not be allocation-neutrale in the present context because of its income effects.
} 
From (12), one can already grasp the basic idea how the proposed model eliminates weak scale effects in BGE (where all variables grow at a constant, possibly zero, rate), along with strong ones. To see this, suppose that - analogous to the vertical innovation model of subsection 2.2 - in the proposed framework the following variables are independent of scale: marginal costs $(\mathfrak{c})$, the number of entrepreneurs per worker $(n=N / L)$, and R\&D inputs $\left(l_{i}^{R}, i \in[0, N]\right)$ which in turn determine the stock of knowledge $(\bar{A})$. In this case, according to (12) but unlike suggested by the expression for income per worker in (2) or (5), $y$ is independent of scale $L$. The remainder of this section shows that such properties indeed hold and derives comparative-static results.

Let $w$ be the wage rate and define $\omega_{t} \equiv w_{t} / \bar{A}_{t}$ ("productivity-adjusted wage rate"). According to (9), cost minimization in the intermediate goods sector implies

$$
\mathfrak{c}_{t}=\beta^{-\beta}(1-\beta)^{-(1-\beta)} \bar{r}^{\beta} \omega_{t}^{1-\beta} \equiv \tilde{\mathfrak{c}}\left(\omega_{t}, \bar{r}\right)
$$

Capital and labor demand in the intermediate goods sector are given by $K=\beta^{1-\beta}(1-$ $\beta)^{-(1-\beta)}(\omega / \bar{r})^{1-\beta} X$ and $L_{t}^{X}=\beta^{-\beta}(1-\beta)^{\beta}(\bar{r} / \omega)^{\beta} X / \bar{A}$, respectively. Using $x_{i}=$ $(\alpha / \mathfrak{c})^{\frac{1}{1-\alpha}} A_{i}$ we find that $X=\int_{0}^{N} x_{i} d i=(\alpha / \mathfrak{c})^{\frac{1}{1-\alpha}} N \bar{A}$. Consequently, we can write

$$
\begin{gathered}
K_{t}=\left(\frac{\beta}{1-\beta} \frac{\omega_{t}}{\bar{r}}\right)^{1-\beta}\left(\frac{\alpha}{\mathfrak{c}_{t}}\right)^{\frac{1}{1-\alpha}} N_{t} \bar{A}_{t} \\
L_{t}^{X}=\left(\frac{1-\beta}{\beta} \frac{\bar{r}}{\omega_{t}}\right)^{\beta}\left(\frac{\alpha}{\mathfrak{c}_{t}}\right)^{\frac{1}{1-\alpha}} N_{t} .
\end{gathered}
$$

An individual $i$ who chooses to become entrepreneur and employs $l_{i}^{R}$ R\&D workers has to invest $(1-\tau) w l_{i}^{R}+w f$ in the first period of life under $\mathrm{R} \& \mathrm{D}$ subsidy rate $\tau$. When saving $s_{i t-1}$ for old age, consumption levels of a member $i$ of generation $t-1$ are given by

$$
c_{i t-1,1}=\left\{\begin{array}{c}
w_{t-1}-s_{i t-1}-(1-\tau) w_{t-1} l_{i t-1}^{R}-w_{t-1} f \text { if } i \text { opens up a firm } \\
w_{t-1}-s_{i t-1} \text { otherwise }
\end{array}\right.
$$


in the first period of life and

$$
c_{i t, 2}=\left\{\begin{array}{c}
(1+\bar{r}) s_{i t-1}+\pi_{i t} \text { if } i \text { is entrepreneur } \\
(1+\bar{r}) s_{i t-1} \text { otherwise }
\end{array}\right.
$$

in the second period of life. Utility function (10) implies that savings are determined by the well-known Euler equation

$$
\frac{c_{i t, 2}}{c_{i t-1,1}}=\rho(1+\bar{r})
$$

Moreover, observing (11) and recalling $\ell_{i t-1}^{R}=a_{i} l_{i t-1}^{R}$, the first-order condition for the optimal R\&D investment of an entrepreneur with ability $a_{i}>0$ can be written as

$$
\frac{c_{i t, 2}}{c_{i t-1,1}}=\rho(1-\alpha)\left(\frac{\alpha}{\mathfrak{c}_{t}}\right)^{\frac{\alpha}{1-\alpha}} \frac{a_{i} h^{\prime}\left(\ell_{i t-1}^{R}\right)}{(1-\tau) \omega_{t-1}} .
$$

Combining (18) and (19), we find that effective R\&D labor investment of entrepreneur $i$ in $t-1$ is given by

$$
\ell_{i t-1}^{R}=\left(h^{\prime}\right)^{-1}\left(\frac{(1+\bar{r})(1-\tau) \omega_{t-1}}{(1-\alpha) a_{i}}\left(\frac{\mathfrak{c}_{t}}{\alpha}\right)^{\frac{\alpha}{1-\alpha}}\right) \equiv \tilde{\ell}^{R}\left(a_{i}, \omega_{t-1}, \mathfrak{c}_{t}, \tau, \bar{r}\right) .
$$

To gain intuition, note that the expression for $\ell_{i t-1}^{R}$ in (20) is equal to the R\&D investment which maximizes the value of net profits of an entrepreneur:

$$
\Pi_{i t-1} \equiv \frac{\pi_{i t}}{1+\bar{r}}-(1-\tau) w_{t-1} l_{i t-1}^{R}-w_{t-1} f
$$

Using $\ell_{i}^{R}=a_{i} l_{i}^{R}$ together with expression (11) for $\pi_{i t}$ and evaluating at $\tilde{\ell}^{R}$, we find that

$$
\begin{gathered}
\frac{\prod_{i t-1}}{\bar{A}_{t-1}}=G\left(a_{i}, \omega_{t-1}, \mathfrak{c}_{t}, \tau, f, \bar{r}\right), \text { where } \\
G(a, \omega, \mathfrak{c}, \tau, f, \bar{r}) \equiv \frac{(1-\alpha)\left(\frac{\alpha}{\mathfrak{c}}\right)^{\frac{\alpha}{1-\alpha}} h\left(\tilde{\ell}^{R}(a, \omega, \mathfrak{c}, \tau, \bar{r})\right)}{(1+\bar{r}) \omega}-\frac{(1-\tau) \tilde{\ell}^{R}(a, \omega, \mathfrak{c}, \tau, \bar{r})}{a}-f .
\end{gathered}
$$

As $h^{\prime \prime}<0,(20)$ implies $\tilde{\ell}_{a}^{R}>0$, i.e., more able entrepreneurs have a higher effective 
R\&D input and thus offer higher product quality. (Subscripts on functions denote partial derivatives throughout.) Moreover, higher future marginal costs in the intermediate good sector and higher (productivity-adjusted) wage rates today, by reducing the future cash-flow $(\pi)$ and raising current $R \& D$ costs, respectively, give a disincentive to invest in $\mathrm{R} \& \mathrm{D}\left(\tilde{\ell}_{\mathfrak{c}}^{R}<0, \tilde{\ell}_{\omega}^{R}<0\right)$. By contrast, a higher $\mathrm{R} \& \mathrm{D}$ subsidy rate raises $\mathrm{R} \& \mathrm{D}$ input $\left(\tilde{\ell}_{\tau}^{R}>0\right)$, all other things being equal.

Individuals become entrepreneurs as long as the utility of doing so exceeds the utility of those who retire in the second period of life. The first result shows that this will be the case as long as the value of net profits is positive, i.e., individuals choose to create a firm if and only if $\Pi_{i t-1} \geq 0$. Proofs are relegated to Appendix B. ${ }^{15}$

Lemma 1. (i) For all $t \geq 1$ and given $\left(\omega_{t-1}, \mathfrak{c}_{t}, \tau, f, \bar{r}\right)$, in equilibrium there is a unique threshold ability level, $\underline{a}_{t}$, which is implicitly defined by $G\left(\underline{a}_{t}, \omega_{t-1}, \mathfrak{c}_{t}, \tau, f, \bar{r}\right)=0$ such that all individuals born in $t-1$ with ability $a \geq \underline{a}_{t}$ become entrepreneur and all other individuals retire when old. (ii) Defining by $\underline{\tilde{a}}(\omega, \tau, f, \bar{r})$ the level of a which is implicitly given by

$$
0=G(\underline{a}, \omega, \tilde{\mathfrak{c}}(\omega, \bar{r}), \tau, f, \bar{r}) \equiv \tilde{G}(\underline{a}, \omega, \tau, f, \bar{r}),
$$

we have $\underline{\tilde{a}}_{\omega}>0, \underline{\tilde{\tilde{a}}}_{\tau}<0$.

Lemma 1 implies that, for a given $\omega$ (the endogenous productivity-adjusted wage rate), a higher $\mathrm{R} \& \mathrm{D}$ subsidy rate $\tau$ fosters entry by reducing $\mathrm{R} \& \mathrm{D}$ costs (i.e., reduces threshold ability level $\underline{a}$ ). A higher $\omega$ impedes entry. Lemma 1 also implies that a share $1-\Phi\left(\underline{a}_{t}\right)$ of the population born in $t-1$ becomes entrepreneur; thus, the number of final good firms in $t$ is given by $N_{t}=L_{t-1}\left(1-\Phi\left(\underline{a}_{t}\right)\right)$. Consequently, observing that $L_{t}=L_{t-1}\left(1+g_{L}\right)$, the equilibrium ratio of (old-aged) entrepreneurs to workers (the

\footnotetext{
${ }^{15}$ Throughout the focus is on interior solutions.
} 
currently young), $n_{t}=N_{t} / L_{t}$, reads

$$
n_{t}=\frac{1-\Phi\left(\underline{a}_{t}\right)}{1+g_{L}} \equiv \tilde{n}\left(\underline{a}_{t}, g_{L}\right)
$$

$t \geq 1$. (Note that $n_{0}=N_{0} / L_{0}$ is given.) For a given threshold ability level, $\underline{a}_{t}, n_{t}$ is decreasing in the population growth rate, $g_{L}$. This is an implication of the assumption that individuals can compete in the final good sector only later in life and are therefore older than workers. ${ }^{16}$

In labor market equilibrium, total labor demand (the sum of labor demand in the intermediate good sector and of future final good producers) is equal to the size of the young population:

$$
L_{t}^{X}+\int_{0}^{N_{t+1}}\left(l_{i t}^{R}+f\right) d i=L_{t} .
$$

This condition implies the following.

Lemma 2. (i) In equilibrium, for all $t \geq 1$, it holds that

$$
\begin{aligned}
0 & =\left(\frac{1-\beta}{\beta} \frac{\bar{r}}{\omega_{t-1}}\right)^{\beta}\left(\frac{\alpha}{\mathfrak{c}_{t-1}}\right)^{\frac{1}{1-\alpha}} n_{t-1}+\int_{\underline{a}_{t}}^{\bar{a}}\left[\frac{\tilde{\ell}^{R}\left(a, \omega_{t-1}, \mathfrak{c}_{t}, \tau, \bar{r}\right)}{a}+f\right] d \Phi(a)-1 \\
& \equiv H\left(\underline{a}_{t}, \omega_{t-1}, \mathfrak{c}_{t-1}, \mathfrak{c}_{t}, n_{t-1}, \tau, f, \bar{r}\right) .
\end{aligned}
$$

A steady state value of a variable $z$ is denoted by $z^{*}$. From Lemma 1 and 2 we find:

Proposition 1. Define

$$
\tilde{H}\left(\underline{a}, \omega, g_{L}, \tau, f, \bar{r}\right) \equiv H\left(\underline{a}, \omega, \tilde{c}(\omega, \bar{r}), \tilde{c}(\omega, \bar{r}), \tilde{n}\left(\underline{a}, g_{L}\right), \tau, f, \bar{r}\right) .
$$

(i) In $B G E\left(\underline{a}^{*}, \omega^{*}\right)$ are unique and simultaneously given by $\tilde{G}\left(\underline{a}^{*}, \omega^{*}, \tau, f, \bar{r}\right)=0$ and

\footnotetext{
${ }^{16}$ It is not clear how relevant this effect is from an empirical point of view. Fortunately, as will become apparent, the main insights drawn from subsequent results are not influenced by the strength of this effect.
} 
$\tilde{H}\left(\underline{a}^{*}, \omega^{*}, g_{L}, \tau, f, \bar{r}\right)=0$ as functions of $\left(g_{L}, \tau, f, \bar{r}\right)$. (ii) An increase in the RED subsidy rate, $\tau$, raises the equilibrium (productivity-adjusted) wage rate, $\omega^{*}$.

That an increase in the $\mathrm{R} \& \mathrm{D}$ subsidy rate, $\tau$, raises $\omega^{*}$ can easily be understood. First, a higher $\tau$ is associated with higher demand for R\&D labor, for a given number of entrepreneurs. Second, it raises the equilibrium share of entrepreneurs, all other things equal (recall $\underline{\tilde{a}}_{\tau}<0$ from Lemma 1), which in turn raises labor demand as well. ${ }^{17}$

One can also show that both the threshold ability value and the (productivityadjusted) wage rate in BGE, $\left(\underline{a}^{*}, \omega^{*}\right)$, are decreasing in $g_{L}$. These results stem exclusively from the impact of a higher $g_{L}$ on $n_{t}=\tilde{n}\left(\underline{a}_{t}, g_{L}\right)$ and may therefore be of minor economic significance. Before we derive implications of changes in $g_{L}$ and $\tau$ for the economy's long-run growth rate, we first address the scale effect issue.

Substituting $\mathfrak{c}_{t}=\tilde{\mathfrak{c}}\left(\omega^{*}, \bar{r}\right)$ and $n_{t}=\tilde{n}\left(\underline{a}^{*}, g_{L}\right)$ into (12), we find that GDP per worker in $\mathrm{BGE}$ is given by

$$
y_{t}^{*}=\bar{A}_{t}\left(\frac{\alpha}{\tilde{\mathfrak{c}}\left(\omega^{*}, \bar{r}\right)}\right)^{\frac{\alpha}{1-\alpha}} \tilde{n}\left(\underline{a}^{*}, g_{L}\right) \equiv \bar{A}_{t} \tilde{y}\left(\underline{a}^{*}, \omega^{*}, g_{L}, \bar{r}\right) .
$$

It is also interesting to look at the capital-labor ratio of the economy, $k=K / L$. Substituting the expression for $\mathfrak{c}_{t}$ from (13) into (14) and using $n_{t}=\tilde{n}\left(\underline{a}^{*}, g_{L}\right)$, we find that

$$
k_{t}^{*}=\bar{A}_{t} \alpha^{\frac{1}{1-\alpha}}\left(\frac{\beta}{\bar{r}}\right)^{\frac{1-\alpha(1-\beta)}{1-\alpha}}\left(\frac{1-\beta}{\omega^{*}}\right)^{\frac{\alpha}{1-\alpha}} \tilde{n}\left(\underline{a}^{*}, g_{L}\right) \equiv \overline{A_{t}} \tilde{k}\left(\underline{a}^{*}, \omega^{*}, g_{L}, \bar{r}\right) .
$$

We obtain the following main result.

Proposition 2. In a BGE, both $y_{t}^{*}$ and $k_{t}^{*}$ are independent of population size (absence of a weak scale effect); for growth rates, we have $g_{y^{*}}=g_{k^{*}}=g_{\bar{A}} \equiv g^{*}$, where the economy's growth rate is also independent of population size (absence of a strong

\footnotetext{
${ }^{17}$ The result of an increase in $\tau$ on the equilibrium threshold level $\underline{a}^{*}$ is however theoretically ambiguous. To see this, note that $\underline{a}^{*}=\underline{\tilde{a}}\left(\omega^{*}, \tau, f, \bar{r}\right)$; thus, $\partial \underline{a}^{*} / \partial \tau=\underline{\tilde{a}}_{\omega} \partial \omega^{*} / \partial \tau+\underline{\tilde{a}}_{\tau}$, where $\underline{\tilde{a}}_{\omega}>0$, $\partial \omega^{*} / \partial \tau>0$ and $\underline{\tilde{\tilde{a}}}_{\tau}<0$.
} 
scale effect) and given by

$$
g^{*}=\frac{1}{1-\Phi\left(\underline{a}^{*}\right)} \int_{\underline{a}^{*}}^{\bar{a}} h\left(\tilde{\ell}^{R}\left(a, \omega^{*}, \tilde{\mathfrak{c}}\left(\omega^{*}, \bar{r}\right), \tau, \bar{r}\right)\right) d \Phi(a)-1 \equiv \tilde{g}\left(\underline{a}^{*}, \omega^{*}, \tau, \bar{r}\right) .
$$

According to Proposition 2, like in neoclassical growth theory and horizontal innovations models like Romer (1990) and Jones (1995a), GDP per worker and the capitallabor ratio grow in BGE at the same rate as the economy's knowledge stock. Why does this not go along with scale effects? To remove strong scale effects, the framework maintained two critical features of the vertical innovation model in section 2. First, the knowledge accessible for innovators equals the past period's average productivity level $(\bar{A})$ rather than, for instance, the sum of productivity levels of firms. Thus, the number of firms, which is positively related to population size, does not matter for the intertemporal knowledge spillover governing sustained growth (Young, 1998). Second, the number of firms per worker, $n=N / L$, is independent of scale in the long-run. The proportionality of the number of firms and scale is consistent with empirical evidence (e.g. Laincz and Peretto, 2006). It therefore is a desirable property. In contrast to standard endogenous growth models like those sketched in section 2, however, GDP is the sum of the value of final output levels of the economy, as defined in national accounting. It is not a function of a Dixit-Stiglitz type of composite commodity of imperfectly substitutable goods. This feature of the proposed framework is of major importance for the result that also weak scale effects are removed, in addition to strong ones.

\subsection{Example and Comparative-Static Results}

As is apparent from expression (31) for the long-run equilibrium growth rate, $g^{*}$, economic policy may affect economic growth in the long-run. An increase in the R\&D subsidy rate $\tau$ directly raises $g^{*}$ by raising $\mathrm{R} \& \mathrm{D}$ investment, for a given share of entrepreneurs and a given productivity-adjusted wage rate in BGE. However, it also affects 
$g^{*}$ through its effects on $\left(\underline{a}^{*}, \omega^{*}\right)$. As these are potentially complex general equilibrium effects, a priori it cannot be ruled out that higher R\&D subsidies may even reduce R\&D-based growth. ${ }^{18}$ For instance, recall from Proposition 2 that an increase in $\tau$ raises the equilibrium wage rate $\omega^{*}$. Higher wages, however, are negatively associated with equilibrium R\&D investment, in turn impeding economic growth, all other things being equal. To quantify the net effect of a change in $\tau$ on the growth rate of per capita income, $g^{*}$, we make use of a numerical example. The example will also be employed to examine the effects of a change in the population growth rate, $g_{L}$.

Example: We specify $h\left(\ell^{R}\right)=1+\sqrt{\ell^{R}}$ and suppose that entrepreneurial ability is uniformly distributed in the unit interval, i.e., $\bar{a}=1$ and the c.d.f. reads $\Phi(a)=a$. The resulting effective R\&D labor input of an entrepreneur with ability $a$ is

$$
\tilde{\ell}^{R}(a, \omega, \mathfrak{c}, \tau, \bar{r})=\left(\frac{(1-\alpha)(\alpha / \mathfrak{c})^{\frac{\alpha}{1-\alpha}} a}{2(1-\tau) \omega(1+\bar{r})}\right)^{2}
$$

according to (20). It can also be shown (available on request) that the threshold level for entrepreneurial ability (above which individuals choose to become entrepreneur), as defined in part (ii) of Lemma 1, is given by

$$
\underline{\tilde{a}}(\omega, \tau, f, \bar{r})=\frac{4(1-\tau) \omega(1+\bar{r})^{2}}{(1-\alpha)^{2}\left(\frac{\alpha}{\mathfrak{c}(\omega, \bar{r})}\right)^{\frac{2 \alpha}{1-\alpha}}}\left(\omega f-\frac{(1-\alpha)\left(\frac{\alpha}{\mathfrak{c}(\omega, \bar{r})}\right)^{\frac{\alpha}{1-\alpha}}}{1+\bar{r}}\right) .
$$

(It is easy to confirm from (33) that $\underline{\tilde{a}}_{\omega}>0$ and $\underline{\tilde{a}}_{\tau}<0$, as generally shown in Lemma 1.) Combining this in the labor market clearing condition, defined in Lemma 2, we

\footnotetext{
${ }^{18}$ See, for instance, Segerstrom (2000) and Grossmann (2007) for models where higher R\&D subsidies may result in slower growth.
} 
find that the unique equilibrium wage rate (adjusted for productivity), $\omega^{*}$, is given by

$$
\begin{aligned}
0= & \left(\frac{1-\beta}{\beta} \frac{\bar{r}}{\omega^{*}}\right)^{\beta}\left(\frac{\alpha}{\mathfrak{c}\left(\omega^{*}, \bar{r}\right)}\right)^{\frac{1}{1-\alpha}} \frac{1}{1+g_{L}}+ \\
& \left(\frac{(1-\alpha)\left(\frac{\alpha}{\mathfrak{c}(\omega, \bar{r})}\right)^{\frac{\alpha}{1-\alpha}}}{(1-\tau) \omega^{*}(1+\bar{r})}\right)^{2} \frac{1+\underline{\tilde{a}}\left(\omega^{*}, \tau, f, \bar{r}\right)}{8}+f-\frac{1}{1-\underline{\tilde{a}}\left(\omega^{*}, \tau, f, \bar{r}\right)}
\end{aligned}
$$

Finally, the long-run growth rate reads

$$
g^{*}=\tilde{g}\left(\underline{a}^{*}, \omega^{*}, \tau, \bar{r}\right)=\left(\frac{\alpha}{\mathfrak{c}\left(\omega^{*}, \bar{r}\right)}\right)^{\frac{1}{1-\alpha}} \frac{(1-\alpha)\left(1+\underline{a}^{*}\right)}{4(1-\tau) \omega^{*}(1+\bar{r})}
$$

where $\underline{a}^{*}=\underline{\tilde{a}}\left(\omega^{*}, \tau, f, \bar{r}\right)$. Interestingly, we have $\tilde{g}_{\underline{a}}(\underline{a}, \omega, \tau, \bar{r})>0$, i.e., a higher fraction of entrepreneurs reduces the economy's growth rate, for a given productivity-adjusted wage rate, $\omega$. This possibility arises because the average productivity across firms in the economy is relevant for income per worker and additional entrepreneurs imply that more mediocre ones are opening firms.

\subsubsection{R\&D subsidies}

$\begin{array}{lllll}\tau & \underline{a}^{*} & \omega^{*} & g^{*} & \Psi \\ 0 & 0.655 & 0.421 & 0.362 & 1.117 \\ 0.1 & 0.656 & 0.423 & 0.397 & 1.126 \\ 0.2 & 0.659 & 0.425 & 0.441 & 1.134 \\ 0.3 & 0.663 & 0.427 & 0.496 & 1.145 \\ 0.4 & 0.670 & 0.431 & 0.567 & 1.154 \\ 0.5 & 0.680 & 0.435 & 0.662 & 1.164\end{array}$

Tab. 1. The impact of an increase in the R\&D subsidy rate $(\tau)$ on the BGE; $\alpha=0.75, \beta=0.3, f=1, \bar{r}=0.2, g_{L}=0.05$.

Tab. 1 shows that both the effective R\&D investment inputs $\left(\tilde{\ell}^{R}\right)$ in BGE and the economy's long-run growth rate are significantly increasing in the R\&D subsidy 
rate, $\tau \cdot{ }^{19}$ This demonstrates that economic growth is policy-dependent in the longrun, in contrast to semi-endogenous growth models. ${ }^{20}$ The negative growth effect of a higher R\&D subsidy which stems from an increase in the productivity-adjusted wage rate, $\omega^{*}$, is clearly dominated by positive growth effects. The effect on the threshold ability level, $\underline{a}^{*}$, i.e., the fraction of individuals not becoming entrepreneur, is reasonably low. ${ }^{21}$ The last column in Tab. 1 shows the relative output of the most able entrepreneur (with ability $\bar{a}=1$ ) to the least able entrepreneur (with ability $\underline{a}^{*}$ ). Recalling $q_{i}=(\alpha / \mathfrak{c})^{\frac{\alpha}{1-\alpha}} A_{i}$ and (8), it equals relative product quality level, defined as

$$
\Psi \equiv \frac{h\left(\tilde{\ell}^{R}(\bar{a}, \cdot)\right)}{h\left(\tilde{\ell}^{R}\left(\underline{a}^{*}, \cdot\right)\right)} .
$$

Relative output level $\Psi$ is increasing in $\tau$. The most able entrepreneur produces between 11.7 percent (for $\tau=0$ ) and 16.4 percent (for $\tau=0.5$ ) more output than the least able entrepreneur.

\subsubsection{The role of population growth}

Endogenous growth models with weak scale effects suggest that the economy's long-run growth rate is increasing in the rate of population growth, $g_{L}$, an implication yet not supported by empirical evidence. According to the framework proposed here, where all scale effects are absent, the population growth rate affects important variables only for a subtle reason: As pointed out already, entrepreneurs are older than workers in the overlapping generations structure. This implies that the number of entrepreneurs relative to workers in a given period, $\tilde{n}\left(\underline{a}, g_{L}\right)$, is decreasing in the rate of population growth, $g_{L}$, holding the threshold ability level constant. As an implication, both $\omega^{*}$ and $\underline{a}^{*}$ are decreasing in $g_{L}$. This leaves the net effect on the long-run growth rate, $g^{*}$,

\footnotetext{
${ }^{19}$ This is confirmed by using a wide range of alternative parameter configurations, not shown here in order to save space. I also experimented with the alternative specification $h\left(\ell^{R}\right)=1+\ln \left(1+\ell^{R}\right)$ and obtained similar results.

${ }^{20}$ The overlapping-generations structure suggests that one period equals one generation. For instance, a compound growth rate $\left(g^{*}\right)$ of 49.6 percent (for $\tau=0.3$ in Tab. 1) implies an annual growth rate of 1.6 percent if the length of a generation is 25 years.

${ }^{21}$ Recall that this effect is generally ambiguous.
} 
ambiguous (for the above example, recall that $\tilde{g}_{\underline{a}}>0$ and $\tilde{g}_{\omega}<0$ ). In any case, due to the minor economic importance of how population growth affects the equilibrium in the proposed model, one may suspect that higher population growth has a rather negligible effect on the important variables.

$\begin{array}{lllll}g_{L} & \underline{a}^{*} & \omega^{*} & g^{*} & \Psi \\ 0 & 0.664 & 0.421 & 0.363 & 1.114 \\ 0.05 & 0.655 & 0.421 & 0.362 & 1.117 \\ 0.1 & 0.645 & 0.421 & 0.360 & 1.121 \\ 0.15 & 0.636 & 0.421 & 0.359 & 1.125 \\ 0.2 & 0.627 & 0.420 & 0.358 & 1.128 \\ 0.25 & 0.619 & 0.420 & 0.356 & 1.132\end{array}$

Tab. 2. The impact of an increase in the R\&D subsidy rate $(\tau)$ on the BGE; $\alpha=0.75, \beta=0.3, f=1, \bar{r}=0.2, \tau=0$.

This is confirmed from Tab. 2, which shows how the variables reported in Tab. 1 depend on $g_{L} \cdot{ }^{22}$ The long-run rate of economic growth is even declining in $g_{L}$, unlike in section 2. However, raising the population growth rate from zero to 25 percent changes $g^{*}$ from 36.3 to 35.6 percent only, which seems to be a rather small impact. Also relative output level $\Psi$ changes only slightly when $g_{L}$ increases.

\section{Concluding Remarks}

The goal of this research was to demonstrate that, contrary to conventional wisdom, the scale of an economy in which long-run economic growth is driven by deliberate R\&D investments of private agents may not play a role for per capita income in the long-run. The analysis was motivated by the mixed empirical evidence even for the weak form of scale effects. It is therefore potentially useful for the agenda of applying general equilibrium models with endogenous technical change to identify the determinants of long-run economic growth.

\footnotetext{
${ }^{22}$ The main conclusions drawn from Tab. 2 are again robust to alternative specifications.
} 
From a theoretical point of view, the analysis and its comparison with previous literature made transparent which assumptions drive (long run) scale effect properties. The framework maintained the basic features of previous vertical innovation models designed to remove strong scale effects; it introduced entrepreneurial innovation and endogenous occupational choice, however, to remove weak scale effects as well.

In the proposed framework, long-run economic growth is sustained also without population growth. It is generally policy-dependent, as shown by allowing for $R \& D$ subsidies. However, there is much scope for extending the model to examine the implications of a wider range of policy measures. Moreover, to focus on the scale effect issue, the analysis has emphasized long-run growth properties and has not addressed issues like stability of the steady state equilibrium or comparative-static effects on the transition path towards it. As is true for previous models of endogenous growth, these are challenging tasks, which are left for future research.

\section{Appendix}

\section{A. BGE of Vertical Innovation Model in Section 2}

Suppose that in the vertical innovation model of section 2.2 there is an infinitely-living representative dynasty with standard intertemporal utility function $U=\sum_{t=0}^{\infty} L_{t} \rho^{t} \ln c_{t}$, $0<\rho<1$, where $c_{t}$ denotes per capita consumption in period $t$. This appendix shows that there exists a symmetric BGE of the model, where the number of goods per worker $(n=N / L)$, the interest rate $(r), \mathrm{R} \& \mathrm{D}$ labor per firm $\left(l^{R}\right)$, and the fraction of labor employed in the final goods sector $\left(l^{Y}=L^{Y} / L\right)$, are time-invariant.

First, note that financial assets per capita, denoted by $\mathfrak{a}$, accumulate according to $\left(1+g_{L}\right) \mathfrak{a}_{t+1}=\left(1+r_{t}\right) \mathfrak{a}_{t}+w_{t}-c_{t}$, where $w_{t}$ denotes the wage rate (recall that $\left.L_{t+1}=\left(1+g_{L}\right) L_{t}\right)$. Utility maximization thus leads to Euler equation $c_{t+1}=\rho\left(1+r_{t}\right) c_{t}$.

The wage rate is equal to the marginal product of labor in the final goods sector; according to (1), $w_{t}=(1-\gamma) Y_{t} / L_{t}^{Y}$. Using $Y_{t}=L_{t} y_{t}$ and expression (5) for $y_{t}$, we find 
that

$$
\tilde{\omega}_{t} \equiv \frac{w_{t}}{\bar{A}_{t} L_{t}}=(1-\gamma)\left(\frac{\gamma^{2}}{r_{t}}\right)^{\frac{\gamma}{1-\gamma}} n_{t} .
$$

Next, combine $p_{i t}=r_{t} / \gamma, x_{i t}=\left(\gamma^{2} / r_{t}\right)^{\frac{1}{1-\gamma}} A_{i t} L_{t}^{Y}$ and (4) to find that the cash-flow of firm $i$ in $t$ is given by

$$
\pi_{i t} \equiv\left(p_{i t}-r_{t}\right) x_{i t}=(1-\gamma) \gamma^{\frac{1+\gamma}{1-\gamma}}\left(r_{t}\right)^{-\frac{\gamma}{1-\gamma}} \bar{A}_{t-1} h\left(l_{i t-1}^{R}\right) L_{t}^{Y}
$$

In period $t-1$, firm $i$ chooses R\&D labor input to maximize the value of net profits $\Pi_{i t-1} \equiv\left(1+r_{t}\right)^{-1} \pi_{i t}-w_{t-1}\left(l_{i t-1}^{R}+f\right)$. In view of (38) and the definition of $\tilde{\omega}$ in (37), the associated first-order condition implies

$$
\frac{(1-\gamma) \gamma^{\frac{1+\gamma}{1-\gamma}}\left(r_{t}\right)^{-\frac{\gamma}{1-\gamma}}}{1+r_{t}} h^{\prime}\left(l_{i t-1}^{R}\right) \frac{L_{t}^{Y}}{L_{t-1}}=\tilde{\omega}_{t-1} .
$$

Due to free entry, in equilibrium, the value of net profits becomes zero. In view of (38) and (39), $\Pi_{i t-1}=0$ implies that for all $i$ and $t$, the equilibrium R\&D labor input, $l^{R *}$, is given by

$$
h\left(l^{R *}\right)-h^{\prime}\left(l^{R *}\right)\left(l^{R *}+f\right)=0
$$

(superscript $\left(^{*}\right)$ denotes steady state values throughout). Thus, $\bar{A}_{t+1} / \bar{A}_{t}=h\left(l^{R *}\right)$, according to (4). It is easy to check that the properties of function $h$ imply that $l^{R *}$ is unique. Moreover, the labor market clearing condition reads $N_{t+1}\left(l^{R *}+f\right)+L_{t}^{Y}=L_{t}$. Thus, $l_{t}^{Y}=L_{t}^{Y} / L_{t}$ can be written as

$$
l_{t}^{Y}=1-n_{t+1}\left(1+g_{L}\right)\left(l^{R *}+f\right) .
$$

From the asset accumulation equation, in BGE, $c_{t+1} / c_{t}=w_{t+1} / w_{t}$. Using $w_{t}=$ $\bar{A}_{t} L_{t} \tilde{\omega}_{t}$ together with the property that $\tilde{\omega}$ is time-invariant in BGE (which will become apparent), we find $c_{t+1} / c_{t}=\left(1+g_{L}\right) h\left(l^{R *}\right)$. From the Euler equation, the equilibrium 
interest rate factor is thus given by

$$
1+r^{*}=\frac{\left(1+g_{L}\right) h\left(l^{R *}\right)}{\rho} .
$$

Using $\tilde{\omega}_{t-1}=\tilde{\omega}_{t}=\tilde{\omega}^{*}, L_{t}=\left(1+g_{L}\right) L_{t-1}, l_{t}^{Y}=L_{t}^{Y} / L_{t}$, and combining (37) with (39), we also find that in BGE $h^{\prime}\left(l^{R *}\right)\left(1+g_{L}\right) l_{t}^{Y}=\gamma\left(1+r^{*}\right) n_{t}$. Substituting (41) and (42), and using $n_{t+1}=n_{t}=n^{*}$ as well as $h\left(l^{R *}\right)=h^{\prime}\left(l^{R *}\right)\left(l^{R *}+f\right)$ from (40), we obtain

$$
n^{*}=\frac{\rho}{\gamma+\rho} \frac{1}{1+g_{L}} \frac{1}{l^{R *}+f}
$$

Combining (41) and (43), we also find that

$$
l^{Y *}=\frac{\gamma}{\gamma+\rho}
$$

It is thus obvious that there exists a BGE where $n, r, l^{R}, l^{Y}$ and $\tilde{\omega}$ are time-invariant. Moreover, using (5), we obtain that in BGE the growth rate of per capita income is given by

$$
g_{y}=\frac{y_{t+1}-y_{t}}{y_{t}}=\frac{\bar{A}_{t+1}}{\bar{A}_{t}} \frac{L_{t+1}}{L_{t}}-1=\left(1+g_{L}\right) h\left(l^{R *}\right)-1
$$

\section{B. Proofs}

Proof of Lemma 1. We first need to solve for individual savings in $t \geq 1$. Substituting (16) and (17) into (18) and observing (11) for entrepreneurs, we find that savings of member $i$ of generation $t-1$, when adjusted to the stock of knowledge, $\mathfrak{s}_{i t-1} \equiv$ $s_{i t-1} / \bar{A}_{t-1}$, are given by

$$
\mathfrak{s}_{i t-1}=\left\{\begin{array}{c}
\tilde{\mathfrak{s}}\left(a_{i}, \omega_{t-1}, \mathfrak{c}_{t}, \tau, \bar{r}, f\right) \text { if } i \text { becomes entrepreneur } \\
\frac{\rho \omega_{t-1}}{1+\rho} \text { otherwise, }
\end{array}\right.
$$


$t \geq 1$, where

$$
\begin{aligned}
\tilde{\mathfrak{s}}(a, \omega, \mathfrak{c}, \bar{r}, f) \equiv & \frac{1}{1+\rho}\left(\rho \omega\left[1-(1-\tau) \frac{\tilde{\ell}^{R}(a, \omega, \mathfrak{c}, \tau, \bar{r})}{a}-f\right]-\right. \\
& \left.(1-\alpha)\left(\frac{\alpha}{\mathfrak{c}}\right)^{\frac{\alpha}{1-\alpha}} \frac{h\left(\tilde{\ell}^{R}(a, \omega, \mathfrak{c}, \tau, \bar{r})\right)}{1+\bar{r}}\right) .
\end{aligned}
$$

Denote utility of an individual $i$ born in $t-1$ who does not become entrepreneur by $U_{i t-1}^{N o n E}$. Substituting (16) and (17) for non-entrepreneurs into (10), we obtain

$$
U_{i t-1}^{N o n E}=(1+\rho) \ln \left(1-\tau_{c}\right)+\rho \ln \rho-(1+\rho) \ln (1+\rho)+(1+\rho) \ln w_{t-1}+\rho \ln (1+\bar{r})
$$

where $\tau_{c}$ denotes the consumption tax rate.

Similarly, let us denote utility of entrepreneur $i$ born in $t-1$ by $U_{i t-1}^{E}$. Substituting consumption levels (16) and (17) for entrepreneurs into (10) and observing (11), $w_{t-1}=$ $\bar{A}_{t-1} \omega_{t-1}, s_{i t-1}=\bar{A}_{t-1} \tilde{\mathfrak{s}}\left(a_{i}, \omega_{t-1}, \mathfrak{c}_{t}, \tau, \bar{r}, f\right)$ and (46), we obtain

$$
\begin{gathered}
U_{i t-1}^{E}=U_{i t-1}^{N o n E}+(1+\rho) \times \\
\ln \left(1-\frac{(1-\tau) \tilde{\ell}^{R}\left(a_{i}, \omega_{t-1}, \mathfrak{c}_{t}, \tau, \bar{r}\right)}{a}-f+(1-\alpha)\left(\frac{\alpha}{\mathfrak{c}_{t}}\right)^{\frac{\alpha}{1-\alpha}} \frac{h\left(\tilde{\ell}^{R}\left(a_{i}, \omega_{t-1}, \mathfrak{c}_{t}, \tau, \bar{r}\right)\right)}{\omega_{t-1}(1+\bar{r})}\right)
\end{gathered}
$$

A member of generation $t-1$ with entrepreneurial ability $a_{i}$ becomes entrepreneur if $U_{i t-1}^{E} \geq U_{i t-1}^{N o n E}$. Using (48) and observing the definition of $G$ in (23), this inequality is equivalent to $G\left(a_{i}, \omega_{t-1}, \mathfrak{c}_{t}, \tau, f, \bar{r}\right) \geq 0$. From (23), we can calculate the partial derivative

$$
G_{a}(a, \cdot)=\tilde{\ell}_{a}^{R}(a, \cdot)\left[\frac{(1-\alpha)\left(\frac{\alpha}{c}\right)^{\frac{\alpha}{1-\alpha}} h^{\prime}\left(\tilde{\ell}^{R}(a, \cdot)\right)}{(1+\bar{r}) \omega}-\frac{1-\tau}{a}\right]+\frac{(1-\tau) \tilde{\ell}_{a}^{R}(a, \cdot)}{a^{2}}
$$

Using (20), by applying the envelope theorem, one finds that the term in squared brackets of (49) is zero; thus, $G_{a}(a, \cdot)>0$. If $\lim _{a \rightarrow 0} G(a, \cdot)<0$, which may hold as $f>0, G(a, \cdot)$ increases, from a negative value for small $a$, as $a$ increases. Hence, 
any ability level $\underline{a}$ such that $G(\underline{a}, \omega, \mathfrak{c}, \tau, \bar{r}, f)=0$ is unique. This confirms part (i). Regarding part (ii), observe first from the definition of $\tilde{G}$ that $G_{a}>0$ implies $\tilde{G}_{a}>0$. Moreover, using again (20), we find $G_{\tau}>0, G_{\omega}<0$ and $G_{\mathfrak{c}}<0$. Together with the facts that $\mathfrak{c}=\tilde{\mathfrak{c}}(\omega, \bar{r})$ and $\tilde{\mathfrak{c}}_{\omega}(\omega, \bar{r})>0$, the latter two properties imply $\tilde{G}_{\omega}=G_{\omega}+G_{\mathfrak{c}} \tilde{\mathfrak{c}}_{\omega}<0$ whereas the first property implies $\tilde{G}_{\tau}>0$. Applying the implicit function theorem, we have $\underline{\tilde{a}}_{\omega}=-\tilde{G}_{\omega} / \tilde{G}_{a}>0$ and $\underline{\tilde{a}}_{\tau}=-\tilde{G}_{\tau} / \tilde{G}_{a}<0$. This concludes the proof.

Proof of Lemma 2. Combining (15) with (26), we obtain

$$
\left(\frac{1-\beta}{\beta} \frac{\bar{r}}{\omega_{t}}\right)^{\beta}\left(\frac{\alpha}{\mathfrak{c}_{t}}\right)^{\frac{1}{1-\alpha}} \frac{N_{t}}{L_{t}}+\frac{1}{L_{t}} \int_{0}^{N_{t+1}}\left(l_{i t}^{R}+f\right) d i=1 .
$$

Using (50) together with (20) confirms (27).

Proof of Proposition 1. Lemma 1 and 2 imply that, in a BGE, $\left(\underline{a}^{*}, \omega^{*}\right)$ are given by $\tilde{G}\left(\underline{a}^{*}, \omega^{*}, \tau, f, \bar{r}\right)=\tilde{H}\left(\underline{a}^{*}, \omega^{*}, g_{L}, \tau, f, \bar{r}\right)=0$. Substituting $\underline{a}=\underline{\tilde{a}}(\omega, \tau, f, \bar{r})$ as defined in part (ii) of Lemma 2 into $\tilde{H}$, we obtain that $\omega^{*}$ is given by

$$
0=\tilde{H}\left(\underline{\tilde{a}}\left(\omega^{*}, \tau, f, \bar{r}\right), \omega^{*}, g_{L}, \tau, f, \bar{r}\right) \equiv \hat{H}\left(\omega^{*}, g_{L}, \tau, f, \bar{r}\right) .
$$

From (27) together with the definition of $\tilde{H}$ and the properties of $\tilde{\ell}^{R}(a, \omega, \mathfrak{c}, \tau, \bar{r})$, $\tilde{n}\left(\underline{a}, g_{L}\right)$ and $\tilde{\mathfrak{c}}(\omega, \bar{r})$ we find that $\tilde{H}_{\underline{a}}<0$ and $\tilde{H}_{\omega}<0$. Also recall from part (ii) of Lemma 1 that $\underline{\tilde{a}}_{\omega}>0$. Hence, $\hat{H}_{\omega}=\tilde{H}_{\underline{a}} \underline{\tilde{a}}_{\omega}+\tilde{H}_{\omega}<0$. Thus, $\omega^{*}$ as given by (51) is unique. This confirms part (i). To prove part (ii), note that $\hat{H}_{\tau}=\tilde{H}_{\underline{a}} \underline{\tilde{a}}_{\tau}+\tilde{H}_{\tau}$. From (27) and (28), we find that $\tilde{H}_{\underline{a}}<0$ and $\tilde{H}_{\tau}>0$, where the latter property stems from the fact that $\tilde{\ell}^{R}$ is increasing in $\tau$. Using $\underline{\tilde{a}}_{\tau}<0$ from Lemma 1 , we thus have $\hat{H}_{\tau}=\tilde{H}_{\underline{a}} \underline{\tilde{a}}_{\tau}+\tilde{H}_{\tau}>0$. Recalling $\hat{H}_{\omega}<0$ and using $\partial \omega^{*} / \partial \tau=-\tilde{H}_{\tau} / \tilde{H}_{\omega}$ also confirms part (ii).

Proof of Proposition 2. According to (8) and the definition of $\bar{A}_{t}$, we find that 
in steady state

$$
\bar{A}_{t}=\frac{\bar{A}_{t-1}}{1-\Phi\left(\underline{a}^{*}\right)} \int_{\underline{a}^{*}}^{\bar{a}} h\left(\tilde{\ell}^{R}\left(a, \omega^{*}, \tilde{\mathfrak{c}}\left(\omega^{*}, \bar{r}\right), \tau, \bar{r}\right)\right) d \Phi(a)
$$

Using (52) confirms that $g_{\bar{A}}$ is given by the right-hand side of (31). From (29) and (30) it is obvious that $y^{*}$ and $k^{*}$ grow at the same rate as well. To confirm that there are neither strong nor weak scale effects, recall that both $\underline{a}^{*}$ and $\omega^{*}$ are independent of population size.

\section{Steady State in a Closed Economy}

This appendix shows that also in a closed economy, where the interest rate is endogenous, there are no scale effects in BGE. To show this, we first employ the additional equilibrium condition for a closed economy that aggregate savings of individuals for old age are equal to capital demand in the intermediate goods sector.

The aggregate capital supply in $t$ is given by

$$
K_{t}=\bar{A}_{t-1} L_{t-1}\left(\Phi\left(\underline{a}_{t}\right) \frac{\rho \omega_{t-1}}{1+\rho}+\int_{\underline{a}_{t}}^{\bar{a}} \tilde{\mathfrak{s}}\left(a, \omega_{t-1}, \mathfrak{c}_{t}, \tau, r_{t}, f\right) d \Phi(a)\right)
$$

To see this, use that a share $\Phi\left(\underline{a}_{t}\right)$ of individuals born in $t-1$ retire in $t$ and that for entrepreneur $i$ born in $t-1, \mathfrak{s}_{i t-1}=\tilde{\mathfrak{s}}\left(a_{i}, \omega_{t-1}, \mathfrak{c}_{t}, \tau, r_{t}, f\right)$ holds in a closed economy.

Next we derive capital demand. Substituting (52) into (14), we obtain

$$
K_{t}=\bar{A}_{t-1} L_{t-1}\left(\frac{\beta}{1-\beta} \frac{\omega_{t}}{r_{t}}\right)^{1-\beta}\left(\frac{\alpha}{\mathfrak{c}_{t}}\right)^{\frac{1}{1-\alpha}} \int_{\underline{a}_{t}}^{\bar{a}} h\left(\tilde{\ell}^{R}\left(a, \omega_{t-1}, \mathfrak{c}_{t}, \tau, r_{t}\right)\right) d \Phi(a)
$$

where we used that $\ell_{i t-1}^{R}=\tilde{\ell}^{R}\left(a_{i}, \omega_{t-1}, \mathfrak{c}_{t}, \tau, r_{t}\right)$ in a closed economy.

Equating supply (53) with demand (54), and rearranging terms leads, for $t \geq 1$, to 


$$
\begin{aligned}
0= & \Phi\left(\underline{a}_{t}\right) \frac{\rho \omega_{t-1}}{1+\rho}+\int_{\underline{a}_{t}}^{\bar{a}} \tilde{\mathfrak{s}}\left(a, \omega_{t-1}, \mathfrak{c}_{t}, \tau, r_{t}, f\right) d \Phi(a)- \\
& \left(\frac{\beta}{1-\beta} \frac{\omega_{t}}{r_{t}}\right)^{1-\beta}\left(\frac{\alpha}{\mathfrak{c}_{t}}\right)^{\frac{1}{1-\alpha}} \int_{\underline{a}_{t}}^{\bar{a}} h\left(\tilde{\ell}^{R}\left(a, \omega_{t-1}, \mathfrak{c}_{t}, \tau, r_{t}\right)\right) d \Phi(a) \\
\equiv & J\left(\underline{a}_{t}, \omega_{t-1}, \omega_{t}, \mathfrak{c}_{t}, \tau, r_{t}, f\right) .
\end{aligned}
$$

We can define $\tilde{J}(\underline{a}, \omega, r, \tau, f) \equiv J(\underline{a}, \omega, \omega, \tilde{\mathfrak{c}}(\omega, r), \tau, r, f)$. In a steady state equilibrium, equilibrium values $\left(\underline{a}^{*}, \omega^{*}, r^{*}\right)$ are therefore given by the equation system $\tilde{G}\left(\underline{a}^{*}, \omega^{*}, \tau, f, r^{*}\right)=\tilde{H}\left(\underline{a}^{*}, \omega^{*}, g_{L}, \tau, r^{*}\right)=\tilde{J}\left(\underline{a}^{*}, \omega^{*}, r^{*}, \tau, f\right)=0$. Thus, $\left(\underline{a}^{*}, \omega^{*}, r^{*}\right)$ are independent of population size. Moreover, we can replace $\bar{r}$ by $r^{*}$ in both (29) and (31) to obtain expressions for the level and growth rate of per capita income in steady state, respectively. This confirms that also in BGE of a closed economy, there are neither weak nor strong scale effects.

\section{References}

Aghion, P. and Howitt, P. (1992). A Model of Growth Through Creative Destruction, Econometrica 60, 323-352.

Ahituv, A. (2001). Be Fruitful or Multiply: On the Interplay Between Fertility and Economic Development, Journal of Population Economics 14, 51-71.

Baumol, W.J., R.E Litan and C.J. Schramm (2007). Sustaining Entrepreneurial Capitalism, Capitalism and Society 2, Issue 2, Article 1, www.bepress.com/cas/vol2/iss2/art1.

Bolaky, B. and C. Freund (2006). Trade, Regulations, and Growth, Paper presented at the Trade and Growth Conference hosted by the IMF, Washington, DC, January 9, 2006.

Brander, J.A. and S. Dowrick (1994). The Role of Fertility and Population in Economic Growth, Journal of Population Economics 7, 1-25.

Clemens, C. (2006). Monopolistic Competition and Entrepreneurial Risk-Taking, 
Economics Letters 93, 68-74.

Dalgaard, C.-J. and C.T. Kreiner (2001). Is Declining Productivity Inevitable?, Journal of Economic Growth 6, 187-203.

Dinopoulos, E. and P. Thompson (1998). Schumpeterian Growth Without Scale Effects, Journal of Economic Growth 3, 313-335.

Dixit, A. and J.E. Stiglitz (1977). Monopolistic Competition and Optimum Product Diversity, American Economic Review 67, 297-308.

Ethier, W.J. (1982) National and International Returns to Scale in the Modern Theory of International Trade, American Economic Review 72, 389-405.

Frankel, J.A. and D. Romer (1999). Does Trade Cause Growth?, American Economic Review 89, 379-399.

García-Peñalosa, C. and J.-F. Wen (2008). Redistribution and Entrepreneurship with Schumpeterian Growth, Journal of Economic Growth 13, 57-80.

Grossman, G. and E. Helpman (1991). Innovation and Growth in the Global Economy, MIT Press, Cambridge (Ma.).

Grossmann, V. (2007). How to Promote R\&D-based Growth? Public Education Expenditure on Scientists and Engineers Versus R\&D-Subsidies, Journal of Macroeconomics 29, 891-911.

Grossmann, V. (2008). Advertising, In-house R\&D, and Growth, Oxford Economic Papers 60, 168-191.

Grossmann, V. and T.M. Steger (2007). Growth, Development, and Technological Change, in: Wei-Bin Zhang (ed.), UNESCO Encyclopedia of Life Support Systems (Mathematical Models in Economics), Eolss Publishers, Oxford, UK.

Groth, C., K.-J. Koch and T.M. Steger (2008). When Economic Growth is Less than Exponential, University of Copenhagen (mimeo).

Hall, R.E. and C.I. Jones (1999). Why Do Some Countries Produce So Much More Output per Worker than Others?, Quarterly Journal of Economics 114, 83-116.

Howitt, P. (1999). Steady Endogenous Growth with Population and R\&D Inputs Growing, Journal of Political Economy 107, 715-730. 
Jones, C.I. (1995a). R\&D-based Models of Economic Growth, Journal of Political Economy 103, 759-784.

Jones, C.I. (1995b). Time Series Tests of Endogenous Growth Models, Quarterly Journal of Economics 110, 495-525.

Jones, C.I. (1999). Growth: With or Without Scale Effects?, American Economic Review Papers and Proceedings 89, 139-144.

Jones, C.I. (2002). Sources of U.S. Economic Growth in a World of Ideas, American Economic Review 92, 220-239.

Jones, C.I. (2005). Growth and Ideas, in: P. Aghion and S. Durlauf (eds.), Handbook of Economic Growth, North-Holland, Amsterdam.

Kelley, A.C. and R.M. Schmidt (2005). Evolution of Recent Economic-demographic Modeling: A Synthesis, Journal of Population Economics 18, 275-300.

Kremer, M. (1993). Population Growth and Technological Change: One Million B.C. to 1990, Quarterly Journal of Economics 108, 681-716.

Laincz, C.A. and P.F. Peretto (2006). Scale Effects in Endogenous Growth Theory: An Error of Aggregation Not Specification, Journal of Economic Growth 11, 263-288.

Lucas, Robert E. (1988). On the Mechanics of Economic Development, Journal of Monetary Economics 22, 3-42.

Peretto, P.F. (1998). Technological Change and Population Growth, Journal of Economic Growth 3, 283-311.

Rodrik, D., A. Subramanian and F. Trebbi (2004). Institutions Rule: The Primacy of Institutions Over Geography and Integration in Economic Development, Journal of Economic Growth 9, 131-165.

Romer, P.M. (1990). Endogenous Technological Change, Journal of Political Economy 98, 71-101.

Rose, A.K. (2006). Size Really Doesn't Matter: In Search of a National Scale Effect, Journal of the Japanese and International Economies 20, 482-507.

Segerstrom, P.S. (1998). Endogenous Growth Without Scale Effects, American Economic Review 88, 1290-1310. 
Segerstrom, P.S. (2000). The Long-run Growth Effects of R\&D Subsidies, Journal of Economic Growth 5, 277-305

Strulik, H. (2005). The Role of Human Capital and Population Growth in R\&Dbased Models of Endogenous Growth, Review of International Economics 13, 129-145.

Strulik, H. (2007). Too Much of a Good Thing? The Quantitative Economics of R\&D-driven Growth Revisited, Scandinavian of Journal Economics 109, 369-386.

Van Praag, M. and P.H. Versloot (2007). What is the Value of Entrepreneurship? A Review of Recent Research, IZA Discussion Paper No. 3014.

Young, A. (1998). Growth Without Scale Effects, Journal of Political Economy 106, 41-63. 